\title{
Geostrategic Significance of Construction of the China-Laos Mohan-Boten Economic Cooperation Zone
}

\author{
Wang Wenhui \\ School of Public Administration, Yunnan University of Finance and Economics.Kunming,Yunnan, China \\ 0871169@163.com
}

\begin{abstract}
In the context of China's "One Belt One Road" strategy and the Laos National Special Zone strategy, the China-Laos Mohan-Boten economic cooperation zone between is of great importance. This paper analyzes the cross-border economic cooperation zone and boundary effects, combs the construction history, objectives and positioning of China-Laos Mohan - Boten economic cooperation zone, focuses on the strategic significance of the cooperation zone in terms of geopolitical, geoeconomic, geopolitical and cultural fields. It is believed that relying on China - Indochina Economic Corridor, the China-Laos Mohan - Boten economic cooperation zone is expected to develop into an important growth pole, and can radiate and drive the development of the surrounding area and along the economic corridor.
\end{abstract}

Keywords-Mohan - Boten; cross-border economic cooperation zone; geopolitics; geoeconomics

\section{INTRODUCTION}

China and Laos jointly construct and develop the China-Laos Mohan - Boten economic cooperation zone. The Chinese side area is located in Mohan town of Xishuangbanna region in Yunnan province, with a planned area of 4.83 square kilometers, the Laos side area is located in Boten economic zone of Namtha Province, with a planned area of 16.4 square kilometers. These two regions are together called "China-Laos Mohan - Boten economic cooperation zone," which is a cross-border economic cooperation zone. As a key hub of China-Indochina economic corridor that connects China and Laos, it is an important node connecting the Silk Road Economic Belt and the 21st Century Maritime Silk Road, and is expected to develop into an important growth pole, so it has prominent location advantages and great geostrategic significance.

\section{CROSS-BORDER ECONOMIC COOPERATION ZONE AND} BOUNDARY EFFECT

With the continuous deepening of China's all-round opening to the outside world, the importance of opening up along the border has been increasingly strengthened in China's opening up strategy. However, due to the complicated and changeable geoeconomic and geopolitical influences, the process of regional international economic integration between China and its neighboring countries is relatively slow, not only hindering China's all-round opening up to the outside world, but also impeding the expectation of provinces along the border of realizing leaping development through the expansion of opening up along the border. Openness realizes the expectation of crossing development. Therefore, the cross-border economic cooperation zone, as an important carrier for dispelling the shield effect and releasing the opening effect of the geopolitical border, cross-border economic cooperation zone has become an important path for provinces along the border to deepen their opening to the outside world.

Cross-border economic cooperation zone is an area in which the opening effect can be fully released. Although the establishment of cross-border economic cooperation zone involves small tariff transfer, the neighboring countries that are sensitive to sovereignty transfer are still very cautious, with the superposition of geopolitical and other factors, Vietnam, Laos, 
Myanmar and other neighboring countries are not enthusiastic toward the construction of cross-border economic cooperation zone recommended by China.

\section{CONSTRUCTION HISTORY, OBJECTIVES AND}

\section{POSITIONING OF CHINA-LAOS MOHAN-BOTEN ECONOMIC COOPERATION ZONE}

Located in the southernmost point of Yunnan Province and bordering the Laos Boten economic zone, Mohan is China's only state-level crossing leading to Laos. As the first leg of the Kunming-Bangkok International Channel (Kunming-Bangkok highway, China-Laos railway, etc.) into Laos, Boten is a national port of Laos.Mohan port was approved as a national first-class port in 1992, and officially opened in 1993.In 2001, ohan border trade zone was officially established,In 2006, it renamed "Mohan economic development zone in Xishuangbanna, Yunnan "In 2007, Kunming-Bangkok highway opened to traffic .In 2010, Mohan Economic Development Zone Administrative Committee and Boten Economic Zone Management Committee signed the "framework agreement for the construction of China Mohan Laos Boten cross-border economic cooperation zone."

In 2013, Yunnan Provincial People's Government and the Lao National Economic Zone Management Committee signed the "framework agreement for the construction of China Mohan - Laos Boten cross-border economic cooperation zone". The Chinese Ministry of Commerce and the Laos National Economic Zone Management Committee signed the "memorandum of understanding on the construction of Mohan - Boten economic cooperation zone".

In July 2015, the State Council approved the establishment of Yunnan Mengla (Mohan) key development and opening test area. In August 2015, the two sides signed the "common overall program for the construction of China-Laos Mohan Boten economic cooperation zone".

According to the common overall program, the two countries are committed to strengthening trade and investment liberalization, personnel exchanges facilitation, infrastructure interoperability, regulatory service efficiency and convenience and other cooperation, strive to build the cooperation area into a demonstration zone for bilateral friendly cooperation between China and Laos and an advanced area for deepening cooperation between China and ASEAN, enhance China-Laos border region competitiveness, and improve the welfare of the people of China and Laos.

According to the "common overall program of China-Laos Mohan - Boten economic cooperation zone", the two countries shall focus on the development of trade, processing and manufacturing, tourism, international finance and modern logistics in the cooperation region in accordance with the principles of complementary advantages, rational distribution and mutual benefit, and will make adjustment according to the development of the zone.

At present, the two sides are accelerating the construction of Mohan - Boten economic cooperation zone, including "hardware" such as infrastructure construction and "software" such as the management mechanism. The construction in Laos side lagged behind at early stage due to financing, but now has begun to advance under the support of China's policy-based financial institutions. The planned five functional areas including Boten international business and financial center, international bonded logistics processing zone, international tourist resort, international parks and Laos ancient city are under construction. The commitment of Laos Customs to retreat 18 kilometers are also in implementation. A special management area of "outside the customs and within the boundary" that enjoys a series of preferential policies will be formed.

Currently, most overland transport of and inbound and outbound tourism in China, Laos and Thailand are transited and distributed through this cooperation zone, and this zone is also a very important node for China to the strategic channel the Moulmein sea port in Burma.

\section{GEOPOLITICAL STRATEGIC SIGNIFICANCE FOR THE}

\section{CONSTRUCTION OF CHINA-LAOS MOHAN - BOTEN ECONOMIC COOPERATION ZONE}

According to the geopolitical theory, the border areas are not only fragmented zones where the territories of countries border on each other, but also strategic zones for safeguarding national security. As marginal areas away from the heart as well as the frontier areas open to the outside world, 
the multiple attributes of border areas determine the significance of establishing spatial connections between border areas and other parts of China and in cross-border areas. With cross-border economic cooperation zone as the important node, and the channel passing through this node that connects China and foreign countries as the axis, it will undoubtedly contribute to the development and opening up of the border areas.[2]

\section{A.Conducive to security and stability in border areas}

Laos is an important way of external communication for the inland areas of Southwest China. The length of China-Laos border line is $710 \mathrm{~km}$.

After the Cold War, traditional military threats were increasingly replaced by smuggling, drug and other non-traditional security threats. Especially the "Golden Triangle" located in the border area of Laos, Thailand and Myanmar has become one of the world's major drug origin. Yunnan Province is adjacent to the "Golden Triangle", with more than 900 kilometers of border line with Laos and Myanmar. Such land accessibility makes the drugs from "Golden Triangle" enter the Chinese border more easily. So China's southwest border has important significance to prevent the flow of drugs into the mainland and safeguard domestic security.

\section{B.Conducive to creating a favorable international environment}

Chinese government attaches great importance to handle the relationship with neighboring countries. The establishment of cross-border economic cooperation zone is significant for implementing China's diplomatic strategy with neighboring countries, promoting economic development in Laos and the opening of Chinese border.

\section{C.Conducive to enhancing the level of cooperation}

between China and Laos and other Southeast Asian countries

The construction of China-Laos Mohan-Boten economic cooperation zone is conducive to linking the most dynamic and promising China with Southeast Asian markets. At the same time, it can also help to narrow the distance between the parties and raise the level of political trust.

\section{Conducive to promoting the implementation of "One}

\section{Belt One Road" strategy}

As an important node of China-Indochina economic corridor, the construction and development of Mohan-Boten economic cooperation zone is indispensable for the construction of whole economic corridor. It will effectively stimulate and promote China and Laos as well as Southeast Asian countries to build "One Belt One Road."

\section{E.Conducive to giving full play to regional advantages in} Yunnan province and northern Laos.

Yunnan is China's only province that opens to the Southeast Asia and South Asia, is the bridge for the communication among three Asian regions (East Asia, Southeast Asia, South Asia) and two oceans (the Pacific Ocean and Indian Ocean). Meanwhile, the northern region of Laos represented by Boten directly borders with China, Thailand, Myanmar and Vietnam. The construction of Mohan-Boten economic cooperation zone will have a huge impact on the economic and social development of that area and surrounding regions, promote the interconnection between China and Southeast Asia, which will help to give full play to the regional advantages in Yunnan province and northern Laos.

\section{GEO-ECONOMIC STRATEGIC SIGNIFICANCE OF}

\section{CHINA-LAOS MOHAN-BOTEN ECONOMIC COOPERATION}

\section{ZONE}

A.Conducive to deepening economic and trade cooperation between China and Laos as well as the ASEAN countries

There should theoretically be "economic zones" In existing cross-border cooperation, e.g. within the ASEAN, between China and its neighboring countries.As a member state of ASEAN, Laos is part of the whole ASEAN economic zone. Mohan-Boten economic cooperation zone will link China-Laos and China - ASEAN closer together.

The construction of the Mohan-Boten Economic Cooperation Zone and relevant channels can not only link China, especially Yunnan, with ASEAN markets such as 
Laos, to promote China's economic influence on Laos and even Southeast Asian countries, help China-ASEAN Free Trade

Area

to

develop constantly, achieve economic communication and integration between China and ASEAN countries, but also can strengthen economic and technological cooperation and competition in a wider range, in a wider field and at a higher level, accelerate the flow of people, logistics, capital and information, promote the rational flow and optimization of production factors, facilitate the common prosperity and development of both markets, improve the level of regional cooperation, and promote common development.

\section{B. Conducive to driving the development of neighborhood} resources and cultivation of advantageous industrial clusters

The border areas are often divided by certain mountains and rivers. Such special geographical conditions are often favorable for the distribution of various resources. In the process of long-term development in history, the border areas, as the "marginal areas" of national development, mainly play the role of separation. Therefore, these areas are more often than not neglected in the country's repeated development plans, and the border areas are the last areas covered in the development of resources.[3]

The future development of border areas depends on the development of resources. According to the "Regional Dependence Theory," the regions on both sides of the border have mutual demands for economic resources and economic development. To break through the passive development pattern featuring "center-periphery" in the past, it is necessary as well as inevitable for border areas to achieve regional development based on their advantages in resources. From the perspective of resource development of border areas, it is important to conduct cross-border cooperation and eliminate disagreements in resource development so as to realize joint develop and win-win results.

Laos is rich in water, minerals, flora and fauna resources, and with abundant tourism resources represented by Luang Prabang and China-Laos border travel. It can make reasonable resource development in the neighborhood relying on the platform or carrier of Mohan - Boten economic cooperation zone. These resources aforementioned five industries that should be given priority for development in the cooperation zone: trade, processing and manufacturing, tourism, international finance and modern logistics, an advantageous industrial cluster is expected to form to further promote the economic development of the cooperation zone and the surrounding area under reasonable distribution guidance of China and Laos.

\section{Conducive to carrying on industrial transfer and} international capacity cooperation in developed regions

Mohan - Boten economic cooperation zone and related channel construction can offer favorable conditions to attract industrial transfer such as low labor costs,short time exports to ASEAN, low logistics cost, etc., contribute to industrial transfer from China's developed areas to cooperation zone, and help China to carry out international capacity cooperation, through which some advantageous but excess capacity can be transferred to needy regions such as Laos.

Chinese enterprises can occupy an advantageous position in the international division of labor by undertaking industrial transfer and carrying out international capacity cooperation. From a global perspective, economic globalization will inevitably be accompanied by dynamic adjustments in the regional distribution of each link of the international industrial chain. Countries and enterprises that can integrate into the global production network can probably achieve great success, but those drifting away from the network. As far as a country is concerned, it may gain benefits or suffer from loss by integrating into economic globalization. Only by making active response, taking the initiative to implement the strategy of "going out", carrying out industrial restructuring and optimizing resource allocation in a broader space will it be possible for a country to occupy an advantageous position in the international division of labor. From this point of view, the construction of the Mohan-Boten Economic Cooperation Zone is of positive significance for China to expand its open space and accelerate its transformation into a trade power in the world. 


\section{Conducive to enhancing the level of infrastructure such} as transportation in China-Indochina economic corridor

As a key hub and node of China-Indochina economic corridor, and an important growth pole, the construction and development of China-Laos Mohan-Boten economic cooperation zone will drive the development of the surrounding area, and boost the development along the China-Indochina economic corridor (especially the Kunming Bangkok channel) .

Kunming-Bangkok highway will soon achieve high speed except Boten - Houeisay section. The high speed construction of Boten - Houeisay section will also be accelerated as a result of the construction of Mohan-Boten economic cooperation zone. Meanwhile, China-Laos railway and China Thailand railway in vision will both exit from Mohan and enter Laos from Boten. The construction of high-speed rail station as well as supporting international bonded logistics park of China-Laos railway in Mohan-Boten economic cooperation zone will strengthen the construction and development of the zone, and vice versa.

\section{CONCLUSION}

In the context of China's "One Belt One Road" strategy and the Laos National Special Zone strategy, and relying on
China-Indochina Economic Corridor, the China-Laos Mohan Boten economic cooperation zone is expected to develop into an important growth pole, and can radiate and drive the development of the surrounding area and along the economic corridor, so it is of great strategic significance in the geopolitical, geo-economic and other fields.

\section{REFERENCES}

[1] 1Mohan Economic Development Zone Administrative Committee and Boten Economic Zone Management Committee , Framework Agreement for the Construction of China Mohan - Laos Boten Cross-border Economic Cooperation Zone,2010.

[2] Yunnan Provincial People's Government and the Lao National Economic Zone Management Committee, Framework Agreement for the Construction of China Mohan - Laos Boten Cross-border Economic Cooperation Zone",2013.

[3] China and Laos,Common Overall Program for the Construction of China-Laos Mohan - Boten Economic Cooperation zone",2015.

[4] He Ming,On the Guangxi University for Nationalities,Vol-38 No.1 Jan,2016.

[5] $\mathrm{Hu}$ Chao,Breakthrough the Border Effect:Urbanization and the Devolpment of Open-Oriented Economy in Border Areas,International Ecnomic and Trade Research,Vol.25 No.8 Aug.2009.

[6] [1] Wang Wenhui,School of Public Administration, Yunnan University of Finance and Economics.

[7] [2] He Ming, On the Guangxi University for Nationalities, Vol-38 No.1 Jan,2016,p130-136.

[8] [3] $\mathrm{Hu}$ Chao,Breakthrough the Border Effect:Urbanization and the Devolpment of Open-Oriented Economy in Border Areas,International Ecnomic and Trade Research,Vol.25 No.8 Aug.2009 